\title{
Heat Transfer Performance of EVAPORON-3 Developed for an Enlarged Heat Transfer Surface of Divertor
}

\author{
Kio TAKAI, Kazuhisa YUKI and Akio SAGARA ${ }^{1)}$ \\ Tokyo University of Science-Yamaguchi, Yamaguchi 756-0884, Japan \\ 1) National Institute for Fusion Science, Oroshicho, Toki 509-5292, Japan
}

(Received 14 February 2017 / Accepted 15 March 2017)

\begin{abstract}
In this study, we newly propose two types of water-cooled divertor devices called EVAPORON-3 using high thermal conductivity porous media that could be applicable especially to an enlarged heat transfer surface such as the divertor plate. Each device has a liquid-vapor separating plate (LVS plate) on the top surface of the porous medium. The LSV plate of the Type-1 device has 9 inlet holes for liquid supply and 12 outlet holes for vapor discharge against a heat transfer surface with the diameter of $30 \mathrm{~mm}$. On the other hand, the LSV plate of the Type-2 device has just one liquid inlet hole at the center of the plate and 12 outlet holes for the vapor discharge. The diameter of each hole is $2.6 \mathrm{~mm}$. The introduced porous medium is a particles-packed bed with the particle diameter of $1.0 \mathrm{~mm}$. In order to reduce pressure loss of the liquid and vapor flows in the porous medium, two layers of the particle are set between the heat transfer surface and the LSV plate. The thickness of the porous bed is $1.82 \mathrm{~mm}$. The result showed that each device enabled a high heat removal of over $5 \mathrm{MW} / \mathrm{m}^{2}$ and, in particular, the Type- 2 device succeeded in the heat flux removal of approximately $11 \mathrm{MW} / \mathrm{m}^{2}$ at the water flow rate of $2 \mathrm{~L} / \mathrm{min}$, although the pressure loss increased by decreasing the number of the inlet holes.
\end{abstract}

(C) 2017 The Japan Society of Plasma Science and Nuclear Fusion Research

Keywords: divertor, high heat flux removal, porous media, water cooling, evaporation, boiling

DOI: $10.1585 /$ pfr.12.1405015

\section{Introduction}

High heat flux removal of approximately $10 \mathrm{MW} / \mathrm{m}^{2}$ at divertors is one of the most important issues in the development of nuclear fusion reactors. The divertor of International Thermonuclear Experimental Reactor (ITER) is cooled by flowing highly subcooled and pressurized water at high speed in a swirl tube that has a twisted-tape inside. In the future, however, new cooling technology that enables energy saving towards the reduction in the cost of electricity should be introduced for development of the demonstration fusion reactors after ITER, because the ITER divertor requires a large pumping power cooling system.

Although several heat removal techniques for the divertor such as gas cooling [1-4] and liquid metal cooling $[5,6]$ have been discussed including water cooling as mentioned above, boiling/evaporation heat transfer utilizing latent heat of vaporization of water could be one candidate from the viewpoint of constructing an efficient cooling system with low pumping power under extremely high heat flux conditions. In order to take full advantage of latent heat of vaporization of water and reduce the pumping power for the cooling system as low as possible, however, we should develop the heat removal device utilizing the evaporative heat transfer rather than the boiling heat transfer.

author'se-mail:kyuki@rs.tusy.ac.jp
In this study, we aim at modifying the heat removal device called EVAPORON [7-9]. EVAPORON utilizes porous media with vast heat transfer surface and complex microchannels, which enables high heat flux removal of $10 \mathrm{MW} / \mathrm{m}^{2}$ due to highly enhanced evaporation of water. However, with increasing heat flux, excessively generated vapor inhibits the liquid supply inside the porous medium, deteriorates the evaporative heat transfer, and then works as a heat insulating layer. In that sense, discharging the generated vapor outside the porous medium could be essential under the extremely high heat flux conditions. To cope with this difficulty, Yuki et al. proposed EVAPORON-2 that utilizes sub-channels-inserted porous media to facilitate the vapor discharge and, as a result, succeeded in the heat removal of over $20 \mathrm{MW} / \mathrm{m}^{2}[10,11]$. However, this device is not suitable for applying it to an enlarged heat transfer surface such as the divertor plate due to the difficulty of assembling it side by side along the divertor plate.

In this study, in order to develop heat removal device EVAPORON-3 that is applicable to the enlarged heat transfer surface, two types of heat removal device with a liquidvapor separating plate on the porous medium are proposed. We verify the validity of introducing the liquid vapor separating plate by experimentally evaluate the heat transfer characteristics of EVAPORON-3 under high heat flux conditions. 


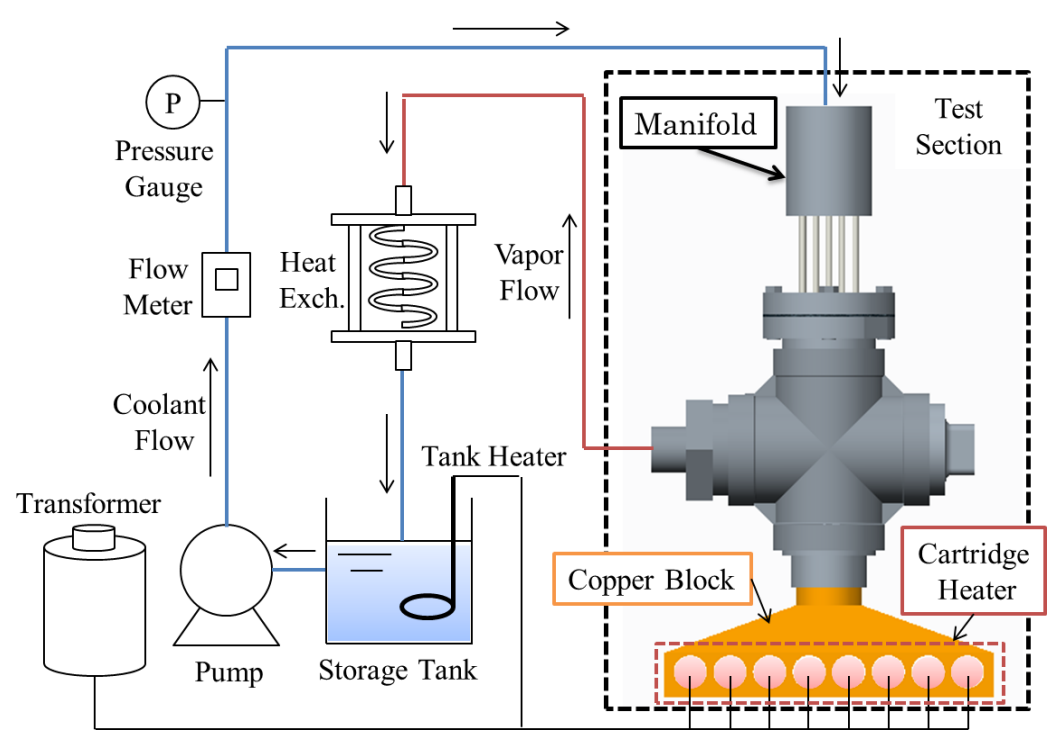

Fig. 1 High heat flux experimental setup using porous media.

\section{Experimental Setup}

Figure 1 shows a system diagram of the experimental apparatus. The experimental apparatus is composed of the coolant supplying section, the heat transfer test section, the vapor discharge section, and the heat exchanger. Distilled water is used as coolant. The coolant supplied with a circulating pump flows into the heat transfer test section, and two-phase flow discharged from the test section is condensed in a spiral type of heat exchanger, and then returned into the pump again. The flow rate is measured with an electromagnetic flowmeter. The inlet and outlet pressures for the test section including the manifold are measured with a Bourdon tube pressure gauge. High power eight cartridge heaters are utilized as high heat flux source and embedded in the bottom part of the heat transfer block made of oxygen free copper (99.95\%). The cross section area of the block is decreased such as a pyramid as shown in Fig. 1 on the right bottom in order to achieve the heat flux of over $10 \mathrm{MW} / \mathrm{m}^{2}$ at the heat transfer surface. The top surface of the cylindrical part of the heat transfer block is a circular heat transfer surface of $30 \mathrm{~mm}$ in diameter. The porous medium is mechanically attached onto this surface. At the axial locations of 3.0, 5.0, 7.0, $9.0 \mathrm{~mm}$ from the heat transfer surface, a K-type of sheathed thermocouple with the diameter of $0.5 \mathrm{~mm}$ is installed at the central axis of the heat transfer block to evaluate the temperature of the heat transfer surface and the heat flux in a steady state.

We propose two types of the heat removal device EVAPORON-3 Type- 1 and Type- 2 as shown in Figs. 2 and 3 , respectively. Each device has a stainless steel liquidvapor separating plate (LVS plate) with the coolant supplying holes and the vapor discharging holes. This liquidvapor separating plate is attached onto the top surface of the porous medium, taking into account applying this device to the large heat transfer surface of divertor by arrang-

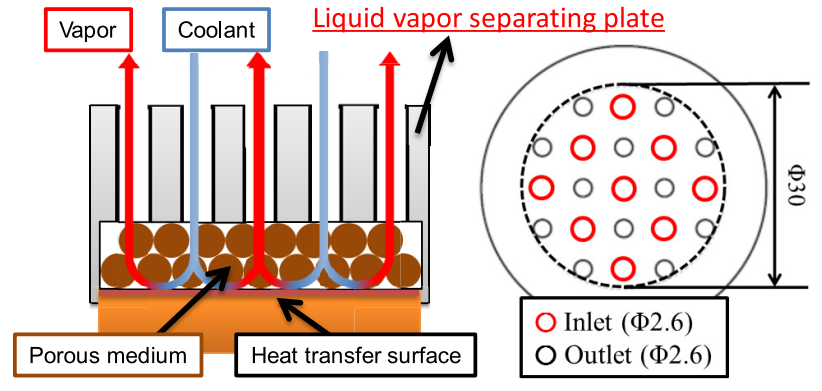

Fig. 2 Heat removal device Type-1.

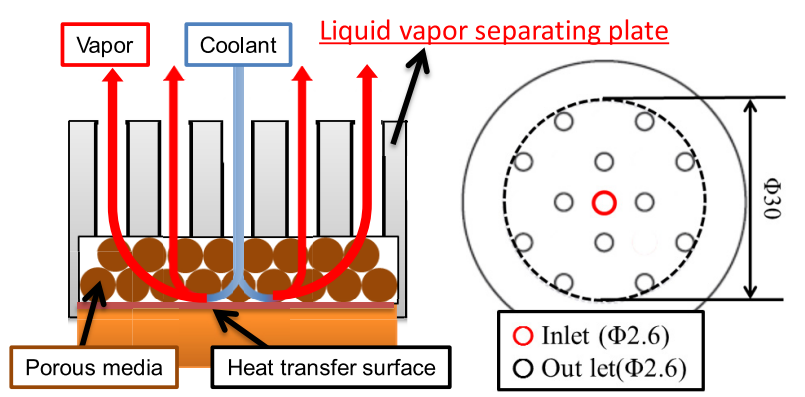

Fig. 3 Heat removal device Type-2.

ing it side by side as shown in Fig. 4. The coolant supplied with the circulation pump is distributed in the manifold (see Fig. 1) into stainless steel pipes with the inner diameter of $2.6 \mathrm{~mm}$ and the thickness of $0.1 \mathrm{~mm}$ that are directly connected to the coolant supplying holes of the LVS plate. The vapor generated in the porous medium is discharged through the vapor discharging holes. The Type1 LVS plate has 9 coolant supplying holes and 12 vapor discharging holes on the top of the porous medium. The Type-2 LVS plate has 12 vapor discharging holes and one coolant supplying hole at the center. The solid black circle 


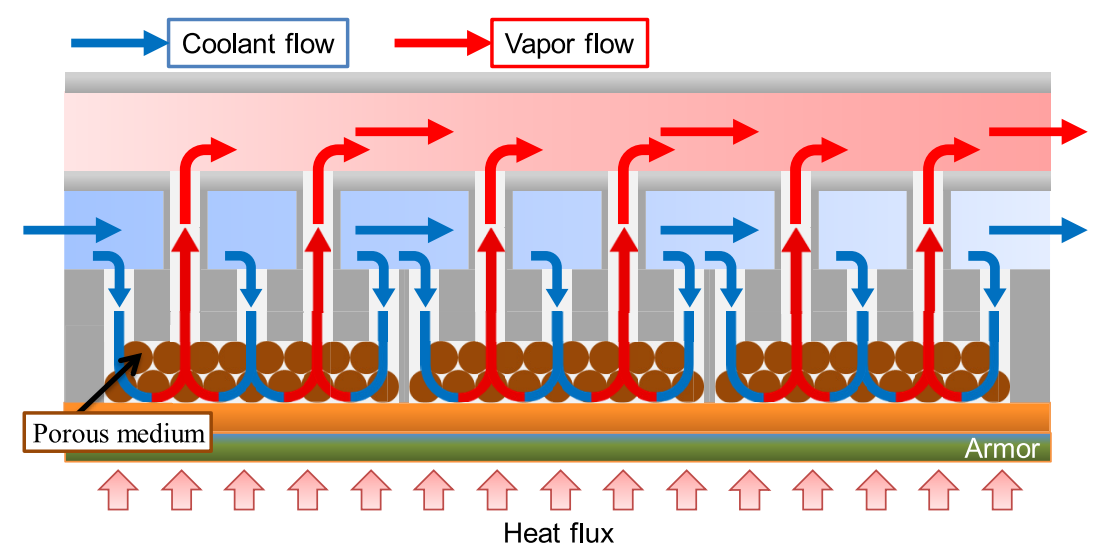

Fig. 4 Conceptual design of divertor cooling by EVAPORON-3.

indicates that the hole is blockaded. The inner diameter of both the inlet and outlet holes is also $2.6 \mathrm{~mm}$ for the Type1 and Type-2 LVS plates. By introducing two types of the heat removal device, we can discuss some issues regarding the phase change of the coolant in EVAPORON-3 and find out the optimum structure of the inlet holes and outlet holes of the LVS plate.

The referential porous medium used in this study is a particles-packed bed that is formed by packing two layers of copper particles with the diameter of $1.0 \mathrm{~mm}$ between the heat transfer surface and the LVS plate. The copper particle we used is made of oxygen free one $(\mathrm{Pu}-$ rity $99.95 \%$ ). Of course, it is possible to replace it to several layers of particle bed or other porous media such as fibrous porous media, particle-sintered porous media, etc. The porosity for the two layered particle bed, which is estimated by counting the number of the particle and calculating the volume of the particles, is $43.4 \%$ and is a little higher than that of the closest particle packing. This is because that this particle bed is formed by 2 layers and that the porosity near the heat transfer surface and the LVS plate is a little higher. The diameter of the packed bed is $30 \mathrm{~mm}$ that is the same as that of the heat transfer surface. The thickness of the bed is $1.82 \mathrm{~mm}$. As to the copper particle, the deviation from spherical form is approximately $\pm 10 \mu \mathrm{m}$. By introducing highly size-adjusted particles, we can obtain a regularly packed bed as shown in Fig. 5. In this study, we utilized larger size of copper particle and thinner porous layer, compared with that of EVAPORON2 developed in the previous works by Yuki et al. $[10,11]$ because we predicted that higher permeability of porous media can work for directly supplying the cooling liquid toward the two-phase region in the porous medium.

In the experiment, the pressure loss characteristics of each device are evaluated in the range from $1.0 \mathrm{~L} / \mathrm{min}$ to $10 \mathrm{~L} / \mathrm{min}$, and then the heat transfer experiment is performed at the flow rate of 2.0 and $5.0 \mathrm{~L} / \mathrm{min}$. The inlet flow velocities for the heat transfer surface of $30 \mathrm{~mm}$ in diameter are $0.047 \mathrm{~m} / \mathrm{s}$ and $0.12 \mathrm{~m} / \mathrm{s}$, respectively. The inlet temperatures are 80 and $30^{\circ} \mathrm{C}$, (The inlet subcoolings

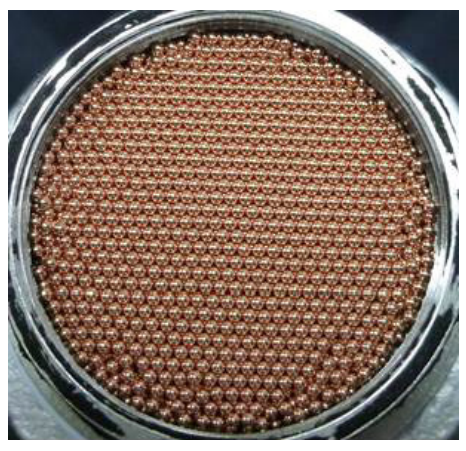

Fig. 5 Porous medium (Packed bed).

are almost 20 and $70 \mathrm{~K}$, respectively). At the fixed flow rate, the input power of the cartridge heaters is increased at a certain interval of voltage. After achieving the steady state and measuring the temperature data, the input power is increased again. The experiment is stopped if the maximum temperature of the heater exceeds $950^{\circ} \mathrm{C}$ or the temperature inside the cylindrical heat transfer block suddenly starts increasing, like critical heat flux phenomenon. The wall temperature, $T_{w}$, is estimated by least squares method using the temperature data inside the cylindrical heat transfer block, and the heat flux, $q$, that flows into the porous medium is evaluated by applying Fourier's law of heat conduction. Heat transfer coefficient is defined as follows.

$$
\text { Heat transfer coef. }\left(\mathrm{W} / \mathrm{m}^{2} / \mathrm{K}\right)=q /\left(T_{\mathrm{w}}-T_{\text {sat }}\right) \text {. }
$$

Where, $T_{\text {sat }}$ is a saturation temperature of cooling water that depends on the inlet pressure. The uncertainty for the heat flux is almost $3.5 \%$ at the heat flux of $10 \mathrm{MW} / \mathrm{m}^{2}$ and $4.5 \%$ at the heat flux of $5 \mathrm{MW} / \mathrm{m}^{2}$. In addition, the uncertainty for the heat transfer coefficient is $5.8 \%$ at the heat flux of $10 \mathrm{MW} / \mathrm{m}^{2}$ and $12.9 \%$ at the heat flux of $5 \mathrm{MW} / \mathrm{m}^{2}$.

\section{Experimental Results}

Figure 6 represents the pressure loss characteristics for each device. The liquid subcooling is $20 \mathrm{~K}$ (Inlet tem- 


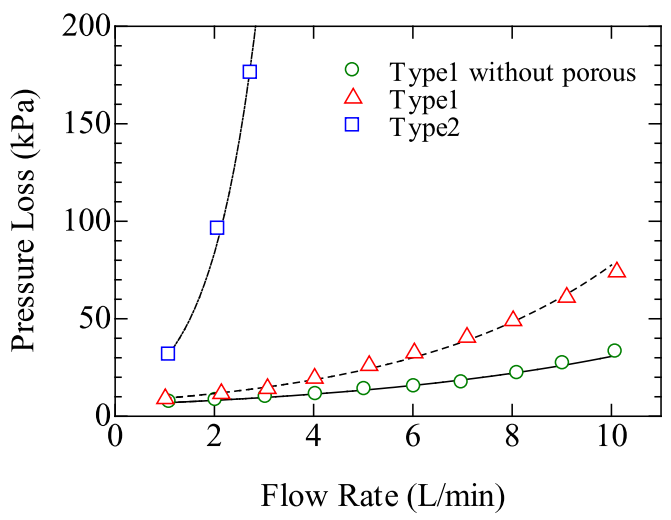

Fig. 6 Pressure loss characteristics of each device.

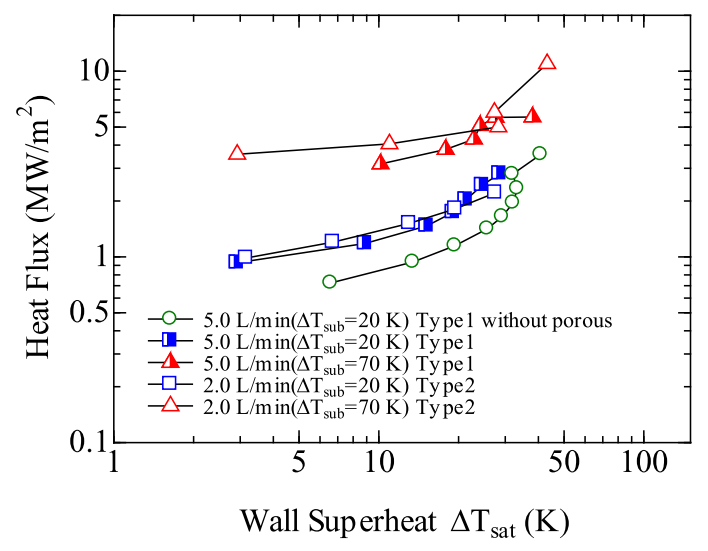

Fig. 7 Heat transfer characteristics of each device.

perature of water is almost $80^{\circ} \mathrm{C}$ ). The pressure loss for each device increases with increasing flow rate. The pressure loss for the Type- 1 device is much higher than that in the case without the porous medium. For instance, the pressure loss of the Type- 1 device is approximately 3 times higher than that without the porous medium at the flow rate of $3 \mathrm{~L} / \mathrm{min}$. However, the range of the pressure loss is from 6 to $80 \mathrm{kPa}$ in the flow rate range from $1 \mathrm{~L} / \mathrm{min}$ to $10 \mathrm{~L} / \mathrm{min}$. On the other hand, the pressure loss of the Type2 device drastically increases and exceeds $200 \mathrm{kPa}$. For instance, the pressure loss of the Type-2 device is almost 9 times higher than that of the Type- 1 device at the flow rate of $2 \mathrm{~L} / \mathrm{min}$. This is due to reduction in the number of the liquid supplying inlet holes of the LVS plate, which drastically increases the flow velocity in the liquid supplying line including the stainless steel small pipes that connects the manifold to the LVS plate. By the way, judging from the inlet pressure and the pressure loss in the stainless steel pipe, the pressure shortly before the porous medium is a little higher than an atmospheric pressure, so that we can assume the inlet saturation temperatures at the flow rates of $2.0 \mathrm{~L} / \mathrm{min}$ and $5.0 \mathrm{~L} / \mathrm{min}$ are almost $100^{\circ} \mathrm{C}$ for both the Type- 1 and Type- 2 devices.

Figure 7 shows boiling curves of the Type- 1 and Type-

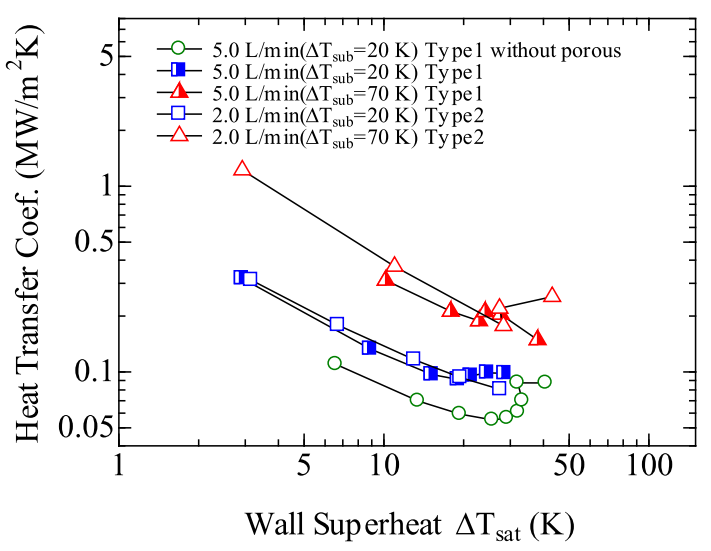

Fig. 8 Heat transfer coefficients of each device.

2 devices. The horizontal axis is the wall superheat that is a temperature difference between the wall temperature and the saturation temperature. The heat transfer performances for both the devices are much higher than that of the Type1 device without the porous medium in which the heat is removed by multiple impinging jets heat transfer. It is confirmed that the heat flux of the Type- 2 device succeeded in the heat removal of $11.0 \mathrm{MW} / \mathrm{m}^{2}$ at the wall superheat of $43.2 \mathrm{~K}$ and the subcooling of $70 \mathrm{~K}$ that is higher than the targeted value of $10 \mathrm{MW} / \mathrm{m}^{2}$. There is worthy of special mention that the heat flux of $11 \mathrm{MW} / \mathrm{m}^{2}$ is removed at a quite low flow rate of $2 \mathrm{~L} / \mathrm{min}$. On the other hand, the maximum heat transfer performance of the Type- 1 device in this experiment is approximately $5.7 \mathrm{MW} / \mathrm{m}^{2}$ at the wall superheat of $38.1 \mathrm{~K}$ and the subcooling of $70 \mathrm{~K}$. It should be noted that the maximum heat flux for both the cases at the subcooling of $70 \mathrm{~K}$ is not the critical heat flux, so that there is a high possibility that these values mentioned above increase more. Furthermore, as shown in Fig. 8, the heat transfer coefficients of the Type- 1 and Type- 2 devices at the same subcooling have almost the similar tendency and equivalent values though the flow rate of the Type- 2 is much lower than that of the Type- 1 device. In the Type- 1 case, the cooling water from the top of the porous medium should flow toward the heat transfer surface and then be discharged ideally as a vapor flow from the top as shown in Fig. 9 on the left. However, judging from Figs. 7 and 8 , with increase in heat flux, it is predicted that excessive amount of vapor is formed by evaporation or boiling on the heat transfer surface and that the water jet is turned back by this vapor pocket as shown in Fig. 9 on the right. In addition, this vapor pocket is pressed by the water jet toward the heat transfer surface, which hampers the discharge of the vapor outside the porous medium. As the results, the temperature of the whole heat transfer surface drastically increased, which leads to suppression of evaporation/boiling heat transfer. Above-mentioned heat removal state can be predicted from the photograph of the heat transfer surface after the experiment shown in Fig. 10. This photograph 


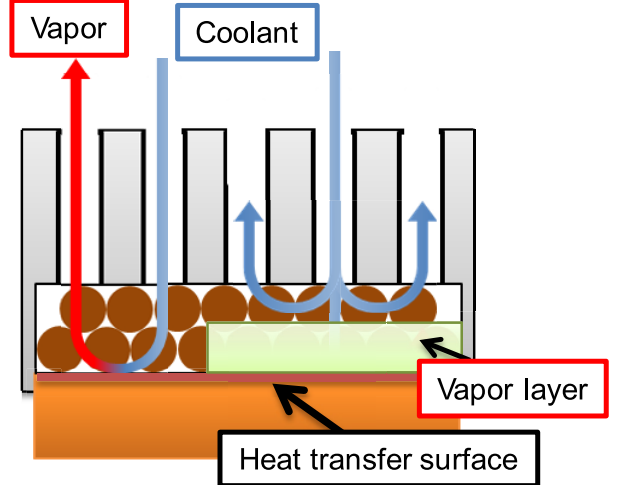

Fig. 9 Prediction of two-phase flow inside Type- 1 of porous medium.
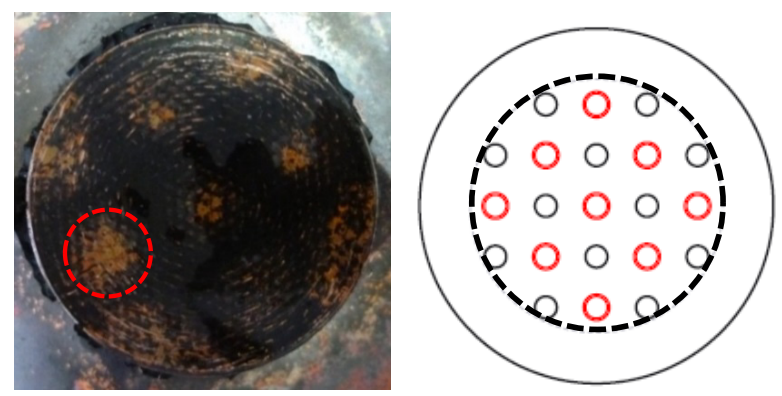

Fig. 10 Photograph of heat transfer surface of Type-1.

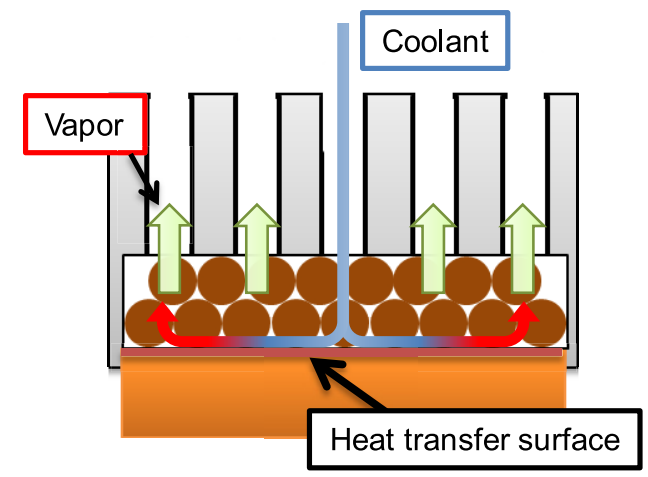

Fig. 11 Prediction of two-phase flow inside Type- 2 of porous medium.

clearly indicates two kinds of region. The first one is copper color regions underneath the coolant inlet holes. Another one is copper oxidation region with black color that corresponds to the formation of completely dry region. On the other hand, in the Type- 2 case, as the coolant is supplied from the one inlet hole at the center of the LVS plate as shown in Fig. 11, it is considered that generated vapor is easily discharged from the vapor outlet holes. In particular, under highly subcooled conditions, the coolant can penetrate the entire porous medium also in a radial direction by changing its phase from a liquid-phase to a two-phase or a vapor-phase, which enables the evaporation in a wider area

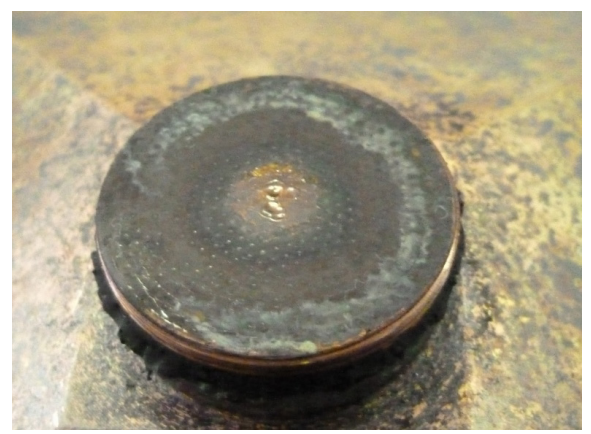

Fig. 12 Photograph of heat transfer surface of Type-2.

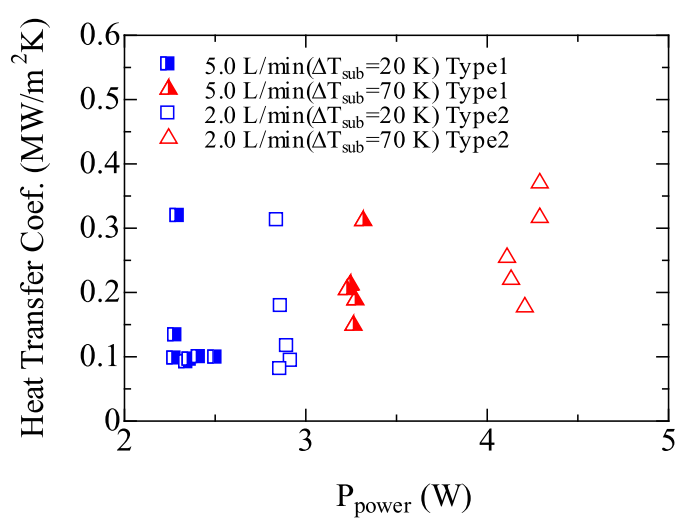

Fig. 13 Heat transfer performance for pumping power.

and leads to the high heat flux removal of over $10 \mathrm{MW} / \mathrm{m}^{2}$. Figure 12 shows the photograph of the heat transfer surface of Type- 2 in which the change in color in a radial direction completely proves the above-mentioned discussion. At the low subcooling of $20 \mathrm{~K}$, however, the coolant immediately seems to evaporate in the porous medium shortly after the inlet holes of the LVS plate, which leads to lower heat transfer coefficients compared with the higher subcooling case of $70 \mathrm{~K}$. These results suggest that there could be an optimal subcooling that depends on the flow rate. Figure 13 shows a relationship between the heat transfer coefficients and the pumping power. It is confirmed that the pumping power at the subcooling of $70 \mathrm{~K}\left(30^{\circ} \mathrm{C}\right)$ is higher than that at the subcooling of $20 \mathrm{~K}\left(80^{\circ} \mathrm{C}\right)$ even at the same device, which proves our prediction that the inlet water is turned back by the generated vapor shortly after the inlet holes and is discharged outside the porous medium, which leads to the decrease in the pressure loss. In addition, although the heat transfer performance of the Type- 2 device at the subcooling of $70 \mathrm{~K}$ indicated maximum one among the present experimental conditions, the pumping power of the Type- 2 device is a little higher than that of the Type- 1 device. This suggests us to make an effort to further reduce the pressure loss of the Type- 2 device. Furthermore, there could be heat flux distribution depending on the structure of the liquid-vapor separating plate, so that the heat flux distribution should be also evaluated in the next step. 


\section{Conclusion}

In this study, two types of water-cooled divertor device that are applicable to the enlarged heat transfer surface were proposed and their boiling/evaporation heat transfer characteristics were evaluated. We succeeded in the heat flux removal of approximately $11 \mathrm{MW} / \mathrm{m}^{2}$ at the flow rate of $2 \mathrm{~L} / \mathrm{min}$ and discussed about some issues of the devices by predicting the two-phase flow state inside the porous medium. Although the pressure losses of both the devices are still of an issue, both the reduction of the pressure loss and further enhancement of the boiling/evaporation heat removal performance could be possible by optimizing the VLS plate and porous structures that can solve the issues mentioned above, regarding to the liquid supply and the vapor discharge.

\section{Acknowledgments}

This work was performed with the support and under the auspices of the National Institute for Fusion Science collaborative research program (NIFS15KERF029).

[1] T. Ihli, A.R. Raffray et al., Fusion Eng. Des. 82, 3 (2007).

[2] S. Sharafat et al., Fusion Sci. Technol. 52, 559 (2007).

[3] S. Sharafat et al., Fusion Sci. Technol. 60, 203 (2011).

[4] V.A. Evtikhin et al., Plasma Phys. Control. Fusion 44, 955 (2002).

[5] R.E. Nygren et al., Liquid Surface Divertor Designs for Fusion Reactors, UCRL-PROC-200896 (2003) p.1-5.

[6] T. Pinna and L.C. Cadwallader, Fusion Eng. Des. 51-52, 579 (2000)

[7] K. Yuki, J. Abei, H. Hashizume and S. Toda, J. Thermal Science 14, no.3, 272 (2005).

[8] K. Yuki, J. Abei, H. Hashizume and S. Toda, ASME J. Heat Transfer 130, Issue 1, 012602 (2008).

[9] K. Yuki, H. Hashizume, S. Toda and K. Suzuki, Special Topics \& Reviews in Porous Media - An International Journal 1, no.1, 1 (2010).

[10] K. Yuki et al., Fusion Sci. Technol. 60, 238 (2011).

[11] K. Yuki et al., Fusion Sci. Technol. 64, 2, 325 (2013). 